\title{
Phospholipid fatty acids analysis of the vertical distribution of microbial communities in eutrophic lake sediments
}

\author{
${ }^{1}$ *D. Y. Zhao; ${ }^{1}$ T. Ma; ${ }^{2}$ J. Zeng; ${ }^{1}$ W. M. Yan; ${ }^{1}$ C. L. Jiang; ${ }^{3}$ J. W. Feng; ${ }^{1}$ Y. N. Xu; ${ }^{1}$ H. Z. Zhao \\ ${ }^{1}$ State Key Laboratory of Hydrology, Water Resources and Hydraulic Engineering, College of Hydrology and \\ Water Resources, Hohai University, Nanjing, China \\ ${ }^{2}$ State Key Laboratory of Lake Science and Environment, Nanjing Institute of Geography and Limnology, Chinese \\ Academy of Sciences, Nanjing, China \\ ${ }^{3}$ School of Civil Engineering, Hefei University of Technology, Hefei, China
}

Received 28 June 2010; $\quad$ revised 24 December 2010; accepted 27 March 2011; $\quad$ available online 1 June 2011

\begin{abstract}
Vertical distribution of microbial communities in a eutrophic lake sediments of Lake Xuanwu was quantified by phospholipid fatty acids analysis and multivariate statistical analysis was employed to interprete the data. Principle component analysis of sediment characteristics parameters, including total nitrogen, total phosphorus, organic matters and $\mathrm{pH}$ produced clustering of sampling sites for two distinct groups. These groups corresponded with the two sampling stations and the levels of nutrient enrichment. Total phospholipid fatty acids concentration, which is indicative of microbial biomass, reduced with depth, however, the relative percentage of anaerobic prokaryotes increased. To assess changes of microbial community along depth, phospholipid fatty acids compositions were analyzed by cluster analysis. Distinct clusters were observed in different sampling stations. Canonical correspondence analysis was carried out to infer the relationship between sediment characteristics and microbial communities. Phospholipid fatty acids samples collected at the same sampling site clustered together. Canonical correspondence analysis revealed that the environmental parameter with the greatest bearing on the phospholipid fatty acids profiles was $\mathrm{pH}$. This study proved the successful application of phospholipid fatty acids and multivariate analysis to investigate the relationship between environment factors and microbial community composition.
\end{abstract}

Keywords: Depth; Lake Xuanwu; Microbes; Multivariate analysis

\section{INTRODCTION}

Lake sediments are vertically structured ecosystems in which microbial activity is predominantly influenced by the availability of nutrient elements and organic matters (OM). The close interchange of chemical, physical and biological processes along vertical gradient also provides niches for metabolically diverse microorganisms. Most previous studies in microbial ecology have focused exclusively on the surface sediment of the lake ecosystem (Amani et al., 2011; Zeng et al., 2008). However, large numbers of microorganisms residing in subsurface sediment, play an important role in nutrient cycling and contaminant degradation (Sahm et al., 1999; Koizumi et al., 2003a; Refaat, 2009). Meanwhile, the microbial communities

凶*Corresponding Author Email: dyzhao@hhu.edu.cn Tel./Fax: +86 2583787891 in the deeper sediments may function differently from those at the surface and their metabolic properties could not be inferred by only studying the microbial communities found in the surface horizons (Ravenschlag et al., 2000; Koizumi et al., 2003b; Ajeagah et al., 2007). There has been several studies concern the investigation of microbial community in the lake sediments based on cultivation, which could not avoid the biases of the true community composition (Jørgensen and Bak, 1991; Parkes et al., 1994; Delille, 1995). Phospholipids are found exclusively in cell membranes and are rapidly metabolized after cell death (Macalady et al., 2000; Mallet et al., 2004). For these reasons, phospholipids could be used to characterize the community structure of viable microorganisms. Phospholipid 
fatty acid analysis (PLFA) is an established method for estimating microbial biomass and analyzing microbial community structure in complex environmental samples (Sundh et al., 2005; Dong et al., 2006; Zink et al., 2008). Additionally, most previous studies only focused on the distribution of pollutants in lake sediments (Nabulo et al., 2008; Nouri et al., 2008; 2009; Harikumar et al., 2009; Atafar et al., 2010; Mohiuddin et al., 2010), the effects of physicochemical factors of the lake sediment on the vertical distribution of microbial community structure should receive more concern (Babel et al., 2009).

Multivariate statistical analysis including principal components analysis (PCA), multidimensional scaling analysis (MDS) and canonical correspondence analysis (CCA) have been proven as promising approaches for investigating the profile of fatty acids.

In these approaches, samples could be clustered to several groups according to their overall similarity, and the effects of environmental parameters could also be considered.

Further analysis of the differentiation between fundamental taxonomic groups such as aerobic and anaerobic is also available. At last, the presence and abundance of discrete biomarkers could be used to assess the changes in the abundance of specific genera or groups (Ben-David et al., 2004; Nwuche and Ugoji, 2010). There have been studies investigating the impacts of acid rock drainage, petroleum hydrocarbon contamination and uranium on the microbial community compositions based on the PLFA and multivariable analysis (Ben-David et al., 2004; Syakti et al., 2006; Small et al., 2008).

These studies showed that different environmental parameters could induce various effects on the changes of microbial community composition. However, the use of PLFA and multivariable analysis to characterize the vertical profile of microbial communities in eutrophic lake sediments was seldom previously described.

This study was carried out at Lake Xuanwu, which is a typical urban, shallow and eutrophic lake located in the north part of Nanjing city in May of 2010. The current status of Lake Xuanwu is eutrophication and the recreational value of this lake is also influenced. By far, there was only few studies concerned the concentrations of nitrogen and phosphorus in the sediment of Lake Xuanwu.

The aim of this study was to investigate the vertical distribution of microbial community present in the sediments of Lake Xuanwu. Additionally, the effects of several environmental factors, such as sampling site, depth, $\mathrm{pH}$, nutrients and $\mathrm{OM}$, on microbial community composition were assessed with multivariate analysis techniques.

\section{MATERIALS AND METHODS}

Study sites

Lake Xuanwu is an urban small $\left(3.71 \mathrm{~km}^{2}\right)$ and shallow (1.14 m mean depth) lake located in the northern part of Nanjing city, Jiangsu province, China. Hydrological information about Lake Xuanwu has been described by Zhang et al. (2007). Two sampling stations were chosen for sediment sampling. The first sampling station S1 $\left(32^{\circ} 05214.523 \mathrm{~N} 118^{\circ} 47217.713\right.$ E) is located near the Nanjing railway station, which is enriched with high concentrations of nitrogen and phosphorus nutrients. The eutrophication of this station was mainly caused by the domestic wastewater discharged from a hotel. The second sampling station $\mathrm{S} 2\left(32^{\circ} 04258.573 \mathrm{~N} 118^{\circ} 47222.923 \mathrm{E}\right)$ is located in the centre of the lake.

Samples collection and measurements of physicochemical parameters

Three replicate sediment samples from each sampling station were collected with a columniform core sampler (DM60, Mingyu, China). The sediment sampler was made of plexiglasses.

The diameter and height of the sampler was 12 and $60 \mathrm{~cm}$. The sampler was connected with a metal bar (length: $1.5 \mathrm{~m}$ ) for sampling and the collected samples were sectioned into six strata with a sterile spatula (0-3, 3-6, 6-11, 11-16, 16-21, 21-26 cm). pH was measured in situ with specific electrodes (PHB-4, REX, China). Three replicate sediment samples for microbial community structure analysis from six depth strata were homogenized and stored at $-80{ }^{\circ} \mathrm{C}$. Sediment samples were dried with a Freeze Dryer (ALPHA 1-2, CHRIST, Germany). Total nitrogen (TN), total phosphorus (TP) and OM were measured according to Jin and $\mathrm{Tu}$ (1990) and the results were expressed as $\mathrm{mg} / \mathrm{g}$ (dry weight). Each sample had three replicates.

\section{Lipid extraction and gas chromatography mass spectrometry (GC-MS) analysis}

Frozen sediment samples (5 g) were extracted overnight by the modified method described by Bligh and Dyer (1959). Phospholipids were converted to 
fatty acid methyl esters (FAME) by heating with $3 \mathrm{~mL}$ of $0.5 \%$ methanolic hydrochloric acid $(\mathrm{HCl})$. Hexane/ chloroform $(4: 1 \mathrm{v} / \mathrm{v})$ were used to extract FAME and the solution was evaporated under a stream of nitrogen. Internal standards of C 20:0 ethyl ester was employed and the FAMEs were dissolved in hexane for chromatographic analysis. FAMEs were stored in $\mathrm{GC}$ vials at $-20^{\circ} \mathrm{C}$ until GC-MS analysis. Samples (1 $\mu \mathrm{L})$ were injected by Triplus autosampler of a DSQ II Single Quadrupole GC/MS (ThermoQuest, San Jose, CA, USA) equipped with a fused-silica DB-5 MS capillary column $(25 \mathrm{~m} \times 0.32 \mathrm{~mm}$ i.d., $0.25 \mu \mathrm{m}$ film thickness). Full scan mode was used for the quantification of FAMEs. Helium was the carrier gas at a constant flow of $1.0 \mathrm{~mL} / \mathrm{min}$. The ion source temperature was maintained at $200{ }^{\circ} \mathrm{C}$. The column was maintained at $50{ }^{\circ} \mathrm{C}$ for $1 \mathrm{~min}$ and the oven was programmed to increase to $260^{\circ} \mathrm{C}$ at $5^{\circ} \mathrm{C} / \mathrm{min}$. Data collection was initiated after the hexane solvent was eluted (3.0 min) and continued until no further peaks were observed. All phospholipid ester-linked FAME were identified based on the relative percentage of the ions scanned and by comparison of retention times to the standard ethyl ester. Concentrations of individual FAME were determined by calibration with internal standard.

\section{Multivariable statistics analysis}

PCA was performed using MVSP 3.13i software package (Kovach Computing, Anglesey, Wales) to study the physicochemical parameters at different depths of the lake sediments. Clustering analysis of the phospholipid fatty acid composition was carried out to investigate the similarities of the microbial community structure in sediment samples.

The relationship between phospholipid fatty acid composition and the sediment physicochemical properties was also investigated. The initial detrended correspondence analysis (DCA) results demonstrated that the data exhibited unimodal rather than linear responses to the environmental variables (Lepš and Šmilauer, 2003; Sapp et al., 2007) so CCA was performed to explain the data by CANOCO 4.5 (Biometris, Wageningen, Netherlands) (Salles et al., 2004; Sapp et al., 2007). Ordination biplots including the phospholipid fatty acid composition and environmental variables were used to explain the data. The detailed interpretation of the ordination plots could be referred to Ter Braak (1987).

\section{RESULTS AND DISCUSSION}

Physicochemical properties of the sediments

The vertical variations of the physicochemical properties of the sediments at two sampling stations are shown in Fig. 1. pH values at station S2 (7.53 to 8.27) are higher than $\mathrm{S} 1$ and it decreased along depth gradually. The concentrations of OM, TN and TP at sampling station S1 ranged from 78.6 to $104.6 \mathrm{mg} / \mathrm{g}$, 3.84 to $7.24 \mathrm{mg} / \mathrm{g}$ and 1.02 to $1.25 \mathrm{mg} / \mathrm{g}$, respectively, which were clearly higher than those of station S2 (OM: 17.4 to $45.9 \mathrm{mg} / \mathrm{g}$; TN: 1.57 to $2.91 \mathrm{mg} / \mathrm{g}$; TP: 0.49 to $0.69 \mathrm{mg} / \mathrm{g}$ ).

The OM concentrations decreased gradually with depth at station S2. However, significant increases of OM were observed at the depths of 13.5 and 18.5 $\mathrm{cm}$ at station $\mathrm{S} 1$. TN contents decreased with depths at station $\mathrm{S} 2$ (2.91 to $1.57 \mathrm{mg} / \mathrm{g})$. However, the highest content of TN was registered at the deeper strata $(18.5 \mathrm{~cm}, 7.24 \mathrm{mg} / \mathrm{g})$ at station S1. Data on TP variations along depths are also presented in Fig. 1. Station S1 presented the higher values of TP, while at station S2 it kept nearly constant with the increased depths (0.49 to $0.69 \mathrm{mg} / \mathrm{g})$. Additionally, the total microbial biomass could be calculated by summation of all detectable PLFAs (Findlay, 1996). In this study, the total concentrations of PLFA varied dramatically at station S1 (1.66 to $8.32 \mu \mathrm{g} / \mathrm{g}$ ) while it decreased with depths gradually at station S2 (12.24 to $2.05 \mu \mathrm{g} / \mathrm{g})$. The PCA ordination of the twelve sediment samples collected from two sampling sites of Lake Xuanwu was shown in Fig. 2a.The first axis and the second axis explained $86.59 \%$ and $8.77 \%$ of the total variance, respectively. Variables such as TN and $\mathrm{OM}$ weighed most heavily on the first axis, while the second axis was better correlated with $\mathrm{pH}$ and TP. Six samples from station S2 formed individual cluster, indicating the relative stable sediment properties in the lake center. Samples collected from S1 station show discrete distribution, which suggests remarkable difference in physicochemical parameters along depth. The influence of domestic wastewater discharged from a hotel near station S1 may explain the elevated nutrient loading and fluctuating physicochemical characteristics at this station.

\section{PLFA composition}

PLFA extracts of sediments samples from Lake Xuanwu were analyzed by gas chromatogram mass analysis and individual PLFA was quantified 
Microbial communities in lake sediments
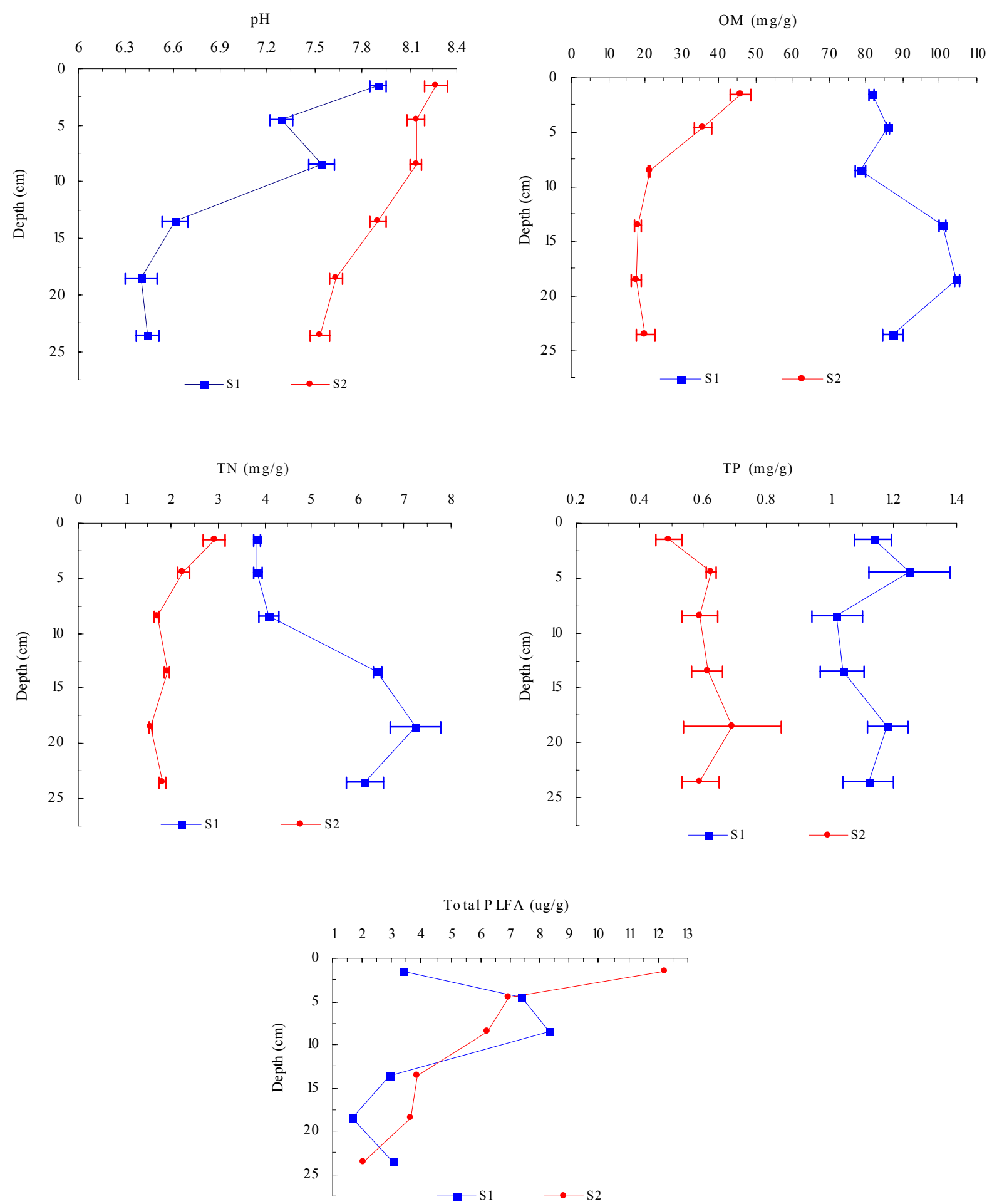

Fig. 1: The vertical variation of the physicochemical parameters in the sediments of Lake Xuanwu. Error bars represent the standard deviation of three replicates 
(Table 1). Twelve kinds of fatty acids containing 15 19 carbon atoms, including saturated (odd and even), chain branched (iso and anteiso) and monounsaturated fatty acids were detected. The PLFA $16: 0,17: 0$ and 17:1w7 were the fatty acids with the highest relative abundance in the samples. Major PLFA components also included a 18:0 and 19:1w8. The relative abundances of saturated fatty acid (SFA) and monounsaturated fatty acid (MUFA) in each sample were also calculated and the results are shown in Table 1.

Dendrograms were constructed based on the relative percentages of fatty acids present in different depths of the lake sediments (Fig. 2b). Generally, sampling stations of S1 and S2 demonstrated distinct clusters, indicating the composition of phospholipid fatty acid differed significantly at the two sites. S1-5 and S2-6 grouped far from the other clusters due to the sharp increase of fatty acids i19:0 and 17:0 at the two strata. These groupings suggest that the sampling stations that had similar sediment characteristics also had similar microbial community composition. Mucha et al. (2004) also reported that similar environmental parameters in the sediment resulted in similar macrobenthic community structures. Fig. 3 shows the vertical changes in the relative abundance of microbial functional groups in sediments of Lake Xuanwu. At station S1 (Fig. 3a), the relative percentage of microbial group I (aerobic prokaryotes) was $33.99 \%$ at the first strata $(0-3 \mathrm{~cm})$ and it decreased gradually with depth, the minimize percentage $(10.42 \%)$ appears at the $16-21 \mathrm{~cm}$ strata. Generally, the relative percentages of gram-positive and other anaerobic bacteria group increased with depth at station S1. The vertical distribution of sulfate reducing bacteria (SRB) increased a little with depth at station S2 (Fig. 3b). However, the relative percentages of gram-positive and other anaerobic bacteria did not show remarkable variations at this station. Aerobic prokaryotes decreased from 37.06 $\%$ in the top stratum to $26.43 \%$ in the deepest stratum. According to Komagata and Suzuki (1987), most of the identified 12 PLFAs in the sediments are affiliated to be prokaryotic. The presence of high proportional MUFAs in all the samples is a further indication of dominated prokaryotes (Ratledge and Wilkinson, 1988). Interpretation of the PLFA data based on the functional group approach revealed aerobic prokaryotes followed by SRB and other

Table 1: Relative percentages of PLFA in different depths of sediments from Lake Xuanwu

\begin{tabular}{|c|c|c|c|c|c|c|c|c|c|c|c|c|}
\hline PLFA & S1-1 & S1-2 & S1-3 & S1-4 & S1-5 & S1-6 & S2-1 & S2-2 & S2-3 & S2-4 & S2-5 & S2-6 \\
\hline i15:0 & 4.07 & 1.72 & 1.18 & 4.25 & 1.83 & 3.17 & 1.93 & 2.25 & 1.3 & 3.3 & 2.33 & 1.8 \\
\hline 15:1w3 & 2.01 & 2.18 & 4.84 & N.D. & 1.05 & 0.47 & 0.2 & 0.1 & 0.1 & 0.1 & 0.1 & 0.1 \\
\hline $15: 0$ & 0.2 & 0.1 & 0.2 & 0.1 & 0.1 & 0.1 & 3.55 & 1.81 & 0.82 & 2.15 & 4.08 & 1.91 \\
\hline $16: 0$ & 12.47 & 15.01 & 10.03 & 15.84 & 8.83 & 14.81 & 18.79 & 15.87 & 11.02 & 13.16 & 16.73 & 10.32 \\
\hline i16:0 & 3.64 & 4.88 & 4.63 & 6.99 & 8.96 & 7.35 & 0.1 & 0.1 & 0.2 & 0.2 & 0.1 & 0.3 \\
\hline $17: 0$ & 23.18 & 26.5 & 25.65 & 31.21 & 26.43 & 34.82 & 22.62 & 26.15 & 27.21 & 28.71 & 26.32 & 35.25 \\
\hline 17:1w7 & 17.51 & 16.49 & 13.43 & 6.03 & N.D. & 5.81 & 15.65 & 17.53 & 15.77 & 12.25 & 13.95 & N.D. \\
\hline a17:0 & 1.83 & 1.91 & 3.5 & 3.91 & 2.82 & 2.42 & 3.71 & 1.75 & 5.39 & 1.41 & 2.21 & 2.13 \\
\hline 18:0 & 0.2 & 0.1 & 0.1 & 0.1 & 0.1 & 0.1 & 1.2 & 4.04 & N.D. & 1.41 & N.D. & 1.6 \\
\hline a18:0 & 13.79 & 13.18 & 21.79 & 12.92 & 7.96 & 10.53 & 4.63 & 4.71 & 5.43 & 5.21 & 3.44 & 6.72 \\
\hline 19:1w8 & 14.47 & 13.05 & 9.25 & 8.49 & 9.33 & 11.11 & 21.21 & 19.63 & 24.83 & 22.25 & 19.51 & 26.33 \\
\hline i19:0 & 6.64 & 4.88 & 5.4 & 10.16 & 32.59 & 9.31 & 6.41 & 6.06 & 7.93 & 9.85 & 11.23 & 13.54 \\
\hline$\Sigma \mathrm{SFA}^{*}$ & 66.02 & 68.28 & 72.48 & 85.48 & 89.62 & 82.61 & 62.94 & 62.74 & 59.3 & 65.4 & 66.44 & 73.57 \\
\hline$\Sigma$ MUFA $^{* *}$ & 33.99 & 31.72 & 27.52 & 14.52 & 10.38 & 17.39 & 37.06 & 37.26 & 40.7 & 34.6 & 33.56 & 26.43 \\
\hline
\end{tabular}

" $\Sigma$ SFA: Saturated fatty acid; ${ }^{* *} \Sigma$ MUFA: Monounsaturated fatty acid 

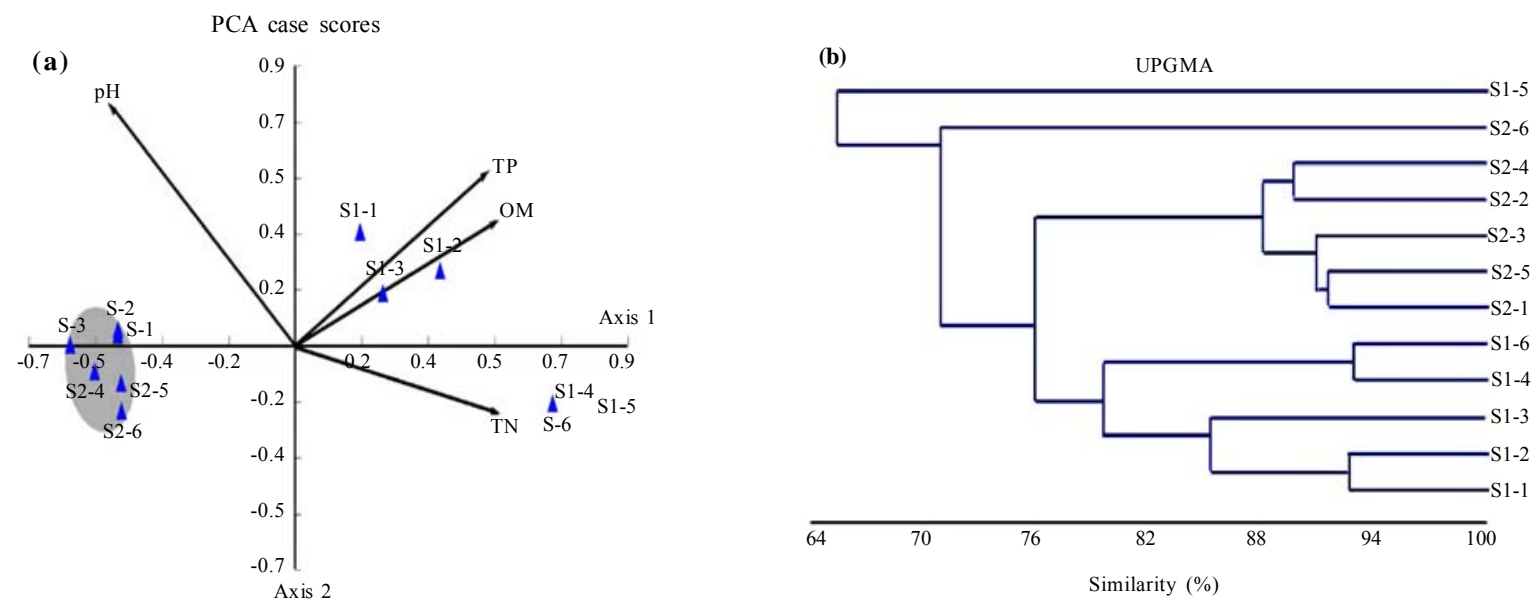

Fig. 2: PCA of the chemical parameters from sediments of Lake Xuanwu (a). Group was indicated with a gray background. Dendrogram for the PLFA from sediments of Lake Xuanwu over different depths (b). Similarities were calculated according to the unweighted pair group method analysis (UPGMA)
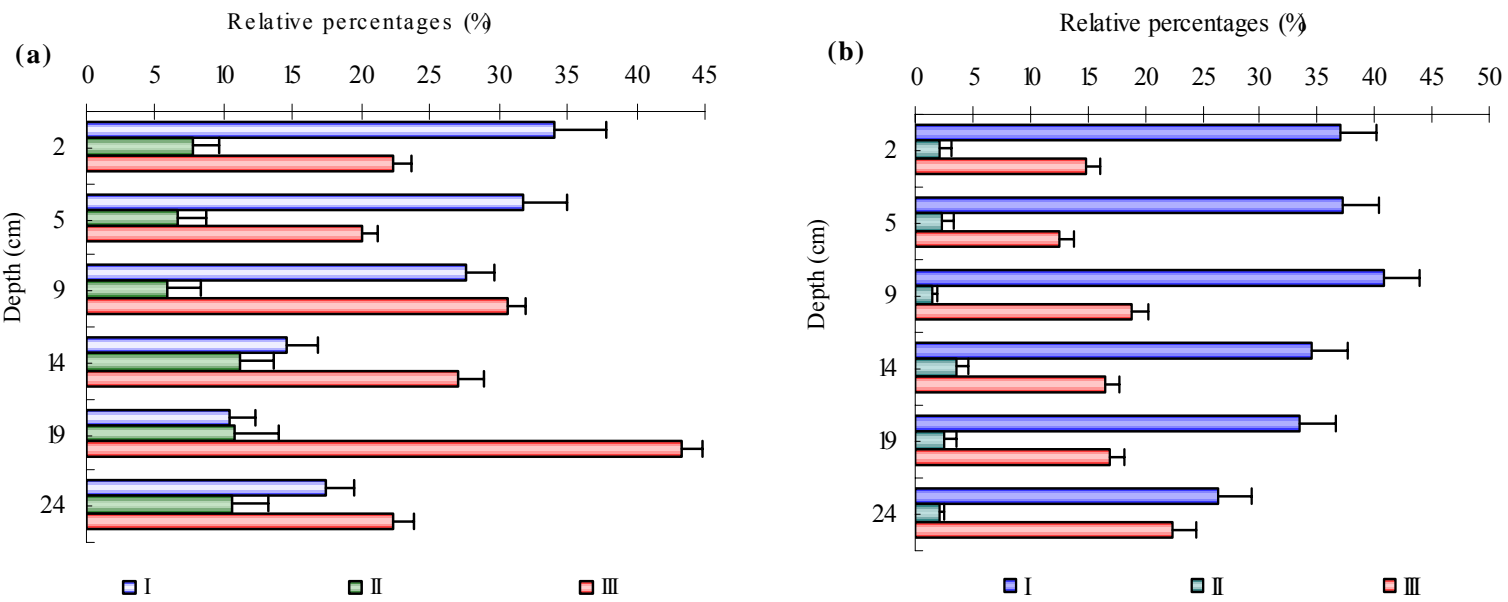

Fig. 3: Vertical changes in the relative abundance of microbial functional groups in sediments of Lake Xuanwu. (a) Station S1; (b) Station S2. I: Aerobic prokaryotes; II: Gram-positive and other anaerobic bacteria; III: SRB and other anaerobic prokaryotes

anaerobic prokaryotes were the predominant components of the prokaryotic community in the sediments (Findlay, 1996). However, SRB may be overestimated due to several SFAs may have a broader phylogenetic distribution. At the same time, a shift in the microbial community structure along depth was observed at both sampling stations. This alteration was manifested by the reduction in relative abundance of aerobic prokaryotes and the increase of SRB and other anaerobic prokaryotes.
Microbial community composition in relation to sediment physicochemical properties

In the freshwater sediment ecosystem, microorganisms play an important role in the process of nutrients transformation and decomposition. Vertical variation of sediment property provides niches for metabolically diverse microorganisms. In this study, the vertical variations of physicochemical factors and phospholipid fatty acid composition in the sediments of Lake Xuanwu were investigated to determine which 
environmental parameter has the strongest effect on microbial community structure (Zink and Mangelsdorf, 2004; Deines et al., 2007; Shrestha et al., 2008; Bodelier et al., 2009; Gómez-Brandón et al., 2010).

CCA is a suitable statistic technique to investigate how microbial community structure varies along gradients of environmental variables (Salles et al., 2004). Bacterioplankton community compositions in relation to water chemistry in marine and freshwater ecosystems have been documented (Rooney-Varga et al., 2005; Haukka et al., 2006; Sapp et al., 2007). However, relationships between the microbial community in sediments and environmental factors were rarely reported.

Biplots consisting of environmental variables and phospholipid fatty acid samples were chosen to analyze the relationship between sediment physicochemical properties and the microbial community composition (Fig. 4). In the ordination plot, the first two CCA axes accounted for $68.0 \%$ of the total variance and the first axis alone explained $40.0 \%$. The microbial community composition clearly clustered according to sampling site rather than sampling depth. Based on the $5 \%$ level in a partial Monte Carlo permutation test, sampling site emerged as a highly significant explanatory variable $(p<0.05)$. However, sampling depth was not a significant environmental variable $(p>0.05)$.

Additionally, environmental parameter that has the

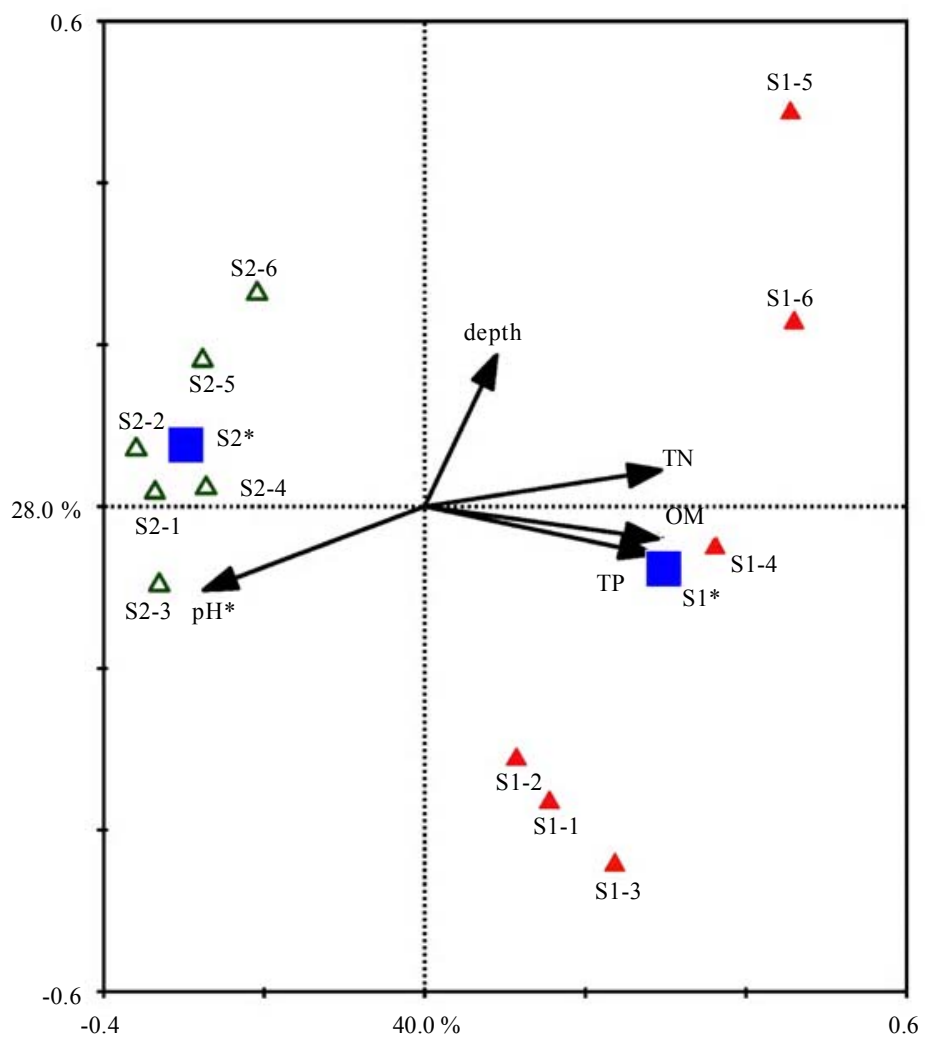

Fig. 4: Ordination diagram of phospholipid fatty acid composition associated with environmental variables of sampling depth, $\mathrm{pH}$, TN, TP and OM. Environmental variables were indicated as arrows. The nominal variable "sampling station" was represented as centroids. Phospholipid fatty acid samples were indicated as $(\mathbf{\Delta})$ Station $S 1,(\Delta)$ Station S2. Environmental variables marked with asterisks were significant $(p<0.05)$ 
greatest bearing on the PLFA profiles was $\mathrm{pH}$. Variation of $\mathrm{pH}$ would influence other environmental factors, such as the availability of ions and trace metals (KoskiVähälä et al., 2001), which could have both stimulative and inhibitory effects on microbial community. However, $\mathrm{pH}$ could also affect microbial community directly by biological mechanisms (Yannarell and Triplett, 2005). In this study, phospholipid fatty acid samples collected at the same sampling site clustered together and sampling depth did not present as a significant environmental factor (Fig. 4). These results were consistent with the previous reports that depthrelated change of the 5 '-terminal restriction fragments of 16S rRNA was small in marine sediment (Urakawa et al., 2000).

Novitsky (1990) also reported that the microbial community structure on the sediment surface was similar to that of sedimenting particles, suggesting that the sediment microbial community originated from sedimenting particles. One possible explanation for the similar community structure between surface and deeper layers of the sediment may be the microorganisms bound on sedimenting particles deposited on the surface and buried. Further studies are needed to investigate the origin and formative process of microbial communities in lake sediments.

\section{CONCLUSION}

In conclusion, the results obtained in this study demonstrated that the PLFA for measuring microbial abundance and community structure could be productively applied to lake sediment. Multivariate statistical methods are effective in explaining the relationship between sediment quality and microbial PLFA. $\mathrm{pH}$ showed remarkable effects on microbial community structure in lake sediments. Investigating the relationship between sediment characteristics and microbial community composition would be useful, because sediment microorganisms play a crucial role in nutrients cycling, which is necessary to maintain aquatic ecosystem health.

\section{ACKNOWLEDGEMENTS}

This work was supported by the Open Foundation from the State Key Laboratory of Hydrology-Water Resources and Hydraulic Engineering at Hohai University ( 2009490611); the National Basic Research Program of China (2008CB418104); the National
Natural Science Foundation of China (41001044), the Project of Nanjing Institute of Geography and Limnology (NIGLAS2010QD10), Natural Science Foundation of Jiangsu Province, China (BK2010522) and the Fundamental Research Funds for the Central Universities of Hohai University (2009B01714), Scientific Research and Development Foundation of Hefei University of Technology (107-036416, GDBJ2009-027).

\section{REFERENCES}

Ajeagah, G.; Njine, T.; Foto, S.; Bilong, C. F. B.; Karanis, P., (2007). Enumeration of Cryptosporidium sp. and Giardia sp. (oo)cysts in a tropical eutrophic lake. Int. J. Environ. Sci. Tech., 4 (2), 223-232 (10 pages).

Amani, T.; Nosrati, M.; Mousavi, S. M.; Kermanshahi, R. K. (2011). Study of syntrophic anaerobic digestion of volatile fatty acids using enriched cultures at mesophilic conditions. Int. J. Environ. Sci. Tech., 8 (1) 83-96 (14 pages).

Atafar, Z.; Mesdaghinia, A.; Nouri, J.; Homaee, M.; Yunesian, M., (2010). Effect of fertilizer application on soil heavy metal concentration. Environ. Monitor. Assess., 160 (14), 83-89 (7 Pages).

Babel, S.; Sae-Tang, J.; Pecharaply, A., (2009). Anaerobic co-digestion of sewage and brewery sludge for biogas production and land application. Int. J. Environ. Sci. Tech., 6 (1) 131-140 (10 pages).

Ben-David, E. A.; Holden, P. J.; Stone, D. J. M., (2004). The use of phospholipid fatty acid analysis to measure impact of acid rock drainage on microbial communities in sediments. Microbial. Ecol., 48 (3), 300-315 (16 pages).

Bligh, E. G.; Dyer, W. J., (1959). A rapid method of total lipid extraction and purification. Can. J. Biochem. Physiol., 37 (8), 911-917 (7 pages).

Bodelier, P. L. E.; Gillisen, M. J. B.; Hordijk, K.; Damsté, J. S. S.; Rijpstra, W. I. C.; Geenevasen, J. A. J.; Dunfield, P. F., (2009). A reanalysis of phospholipid fatty acids as ecological biomarkers for methanotrophic bacteria. ISME J., 3 (5), 606-617 (12 pages).

Deines, P.; Bodelier, P.L.E.; Eller, G., (2007). Methane derived carbon flows through methane oxidizing bacteria to higher trophic levels in aquatic systems. Environ. Microbiol., 9 (5), 1126-1134 (9 pages).

Delille, D., (1995). Seasonal changes of subantarctic benthic bacterial communities. Hydrobiologia, 310 (1), 45-57 (13 pages).

Dong, H. L.; Zhang, G. X.; Jiang, H. C., (2006). Microbial diversity in sediments of saline Qinghai Lake, China: Linking geochemical controls to microbial ecology. Microbial Ecol., 51 (1), 65-82 (18 pages).

Findlay, R. H., (1996). The use of phospholipid fatty acids to determine microbial community structure. Akkermans, A. D. L.; Van Elsas, J. D.; De Bruijn, F. J., (Eds.). Molecular Microbial Ecology Manual. Kluwer Academic Publishers, Dordrecht.

Gómez-Brandón, M.; Lores, M.; Domínguez, J., (2010). A new combination of extraction and derivatization methods that reduces the complexity and preparation time in 
determining phospholipid fatty acids in solid environmental samples. Biores. Tech., 101 (4), 1348-1354 (7 pages).

Harikumar, P. S.; Nasir, U. P.; Rahman, M. P. M., (2009). Distribution of heavy metals in the core sediments of a tropical wetland system. Int. J. Environ. Sci. Tech., 6 (2), 225-232 (8 pages).

Haukka, K.; Kolmonen, E.; Hyder, R., (2006). Effect of nutrient loading on bacterioplankton community composition in Lake Mesocosms. Microbial Ecol., 51 (2), 137-146 (10 pages).

Jin, X. C.; Tu, Q. Y., (1990). Survey specification for Lake eutrophication. Environmental Science Press, Beijing.

Jørgensen, B. B.; Bak, F., (1991). Pathways and microbiology of thiosulfate transformations and sulfate reduction in marine sediment (Kattegat, Denmark). Appl. Environ. Microbiol., 57 (3), 847-856 (10 pages).

Koizumi, Y.; Takii, S.; Nishino, M., (2003a). Vertical distributions of sulfate-reducing bacteria and methaneproducing archaea quantified by oligonucleotide probe hybridization in the profundal sediment of a mesotrophic lake. FEMS Microbiol. Ecol., 44 (1), 101-108 (8 pages).

Koizumi, Y.; Kojima, H.; Fukui, M., (2003b). Characterization of depth-related microbial community structure in lake sediment by denaturing gradient gel electrophoresis of amplified 16S rDNA and reversely transcribed 16S rRNA fragments. FEMS Microbiol. Ecol., 46 (2), 147-157 (11 pages)

Komagata, K.; Suzuki, K. I., (1987). Lipid and cell wall analysis in bacterial systematics, in: Colwell, RR, Grigorova, R (Eds.), Methods in Microbiology, Academic Press, London.

Koski-Vahala, J.; Hartikainen, H.; Tallberg, P., (2001). Phosphorus mobilization from various sediment pools in response to increased $\mathrm{pH}$ and silicate concentration. J. Environ. Qual., 30 (2), 546-552 (7 pages).

Lepc, J.; milauer, P., (2003). Multivariate analysis of ecological data using CANOCO. Cambridge University Press, Cambridge.

Macalady, J. L.; Mack, E. E.; Nelson, D. C., (2000). Sediment microbial community structure and mercury methylation in mercury-polluted clear lake, California. Appl. Environ. Microbiol., 66 (4), 1479-1488 (10 pages).

Mallet, C.; Basset, M.; Fonty, G., (2004). Microbial population dynamics in the sediments of a eutrophic lake (Aydat, France) and characterization of some heterotrophic bacterial isolates. Microbial Ecol., 48 (1), 66-77 (12 pages).

Mohiuddin, K.M.; Zakir, H. M.; Otomo, K.; Sharmin, S.; Shikazono, N., (2010). Geochemical distribution of trace metal pollutants in water and sediments of downstream of an urban river. Int. J. Environ. Sci. Tech., 7 (1), 17-28 (12 pages).

Mucha, A.P.; Vasconcelosb, M. T .S. D.; Bordaloa, A. A., (2004). Vertical distribution of the macrobenthic community and its relationships to trace metals and natural sediment characteristics in the lower Douro estuary, Portugal. Estuar. Coast. Shelf. Sci., 59 (4), 663-667 (5 pages).

Nabulo, G.; Origa, H. O.; Nasinyama, G. W.; Cole, D., (2008). Assessment of $\mathrm{Zn}, \mathrm{Cu}, \mathrm{Pb}$ and $\mathrm{Ni}$ contamination in wetland soils and plants in the lake victoria basin. Int. J. Environ. Sci. Tech., 5 (1), 65-74 (10 pages).
Nouri, J.; Danehkar, A.; Sharifipour, R., (2008). Evaluation of ecotourism potential in the northern coastline of the Persian Gulf. Environ. Geo., 55 (3), 681-686 (6 pages).

Nouri, J.; Khorasani, N.; Lorestani, B.; Karami, M.; Hassani, A. H.; Yousefi, N., (2009). Accumulation of heavy metals in soil and uptake by plant species with phytoremediation potential. Environ. Earth Sci., 59 (2), 315-323 (9 pages).

Novitsky, J. A., (1990). Evidence for sedimenting particles as the origin of the microbial community in a coastal marine sediment. Mar. Ecol. Prog. Ser., 60, 161-167 (7 pages).

Nwuche, C. O.; Ugoji, E. O., (2010). Effect of co-existing plant specie on soil microbial activity under heavy metal stress. Int. J. Environ. Sci. Tech., 7 (4) 697-704 (8 pages).

Parkes, R. J.; Cragg, B. A.; Bale, S. J., (1994). Deep bacterial biosphere in Pacific Ocean sediments. Nature, 371, 410413 (4 pages).

Ratledge, C.; Wilkinson, S. G., (1988). Microbial Lipids. Academic Press, London.

Ravenschlag, K.; Sahm, K.; Knoblauch, C., (2000). Community structure, cellular rRNA content, and activity of sulfatereducing bacteria in marine arctic sediments. Appl. Environ. Microbiol., 66 (8), 3592-3602 (11 pages).

Refaat, A. A., (2009). Correlation between the chemical structure of biodiesel and its physical properties. Int. J. Environ. Sci. Tech., 6 (4) 677-694 (18 pages).

Rooney-Varga, J. N.; Giewat, M. W.; Savin, M. C., (2005). Links between phytoplankton and bacterial community dynamics in a costal marine environment. Microbial Ecol., 49 (1), 163-175 (13 pages).

Sahm, K.; MacGregor, B. J.; Jørgensen, B. B., (1999). Sulphate reduction and vertical distribution of sulphate-reducing bacteria quantified by rRNA slot-slot hybridization in a coastal marine sediment. Environ. Microbiol., 1 (1), 65-74 (10 pages).

Salles, J. F.; van Veen, J. A.; van Elsas, J. D., (2004). Multivariate analysis of Burkholderia species in soil: effect of crop and land use history. Appl. Environ. Microbiol., 70 (7), 40124020 (9 pages).

Sapp, M.; Wichels, A.; Wiltshire, K.H., (2007). Bacterial community dynamics during the winter-spring transition in the North Sea. FEMS Microbiol. Ecol., 59 (3), 622-637 (6 pages).

Shrestha, M.; Abraham, W. R.; Shrestha, P. M.; Noll, M.; Conrad, R., (2008). Activity and composition of methanotrophic bacterial communities in planted rice soil studied by flux measurements, analyses of pmoA gene and stable isotope probing of phospholipid fatty acids. Environ. Microbiol., 10(2), 400-412 (13 pages).

Small, J.A.; Bunn, A.; McKinstry C., (2008). Investigating freshwater periphyton community response to uranium with phospholipid fatty acid and denaturing gradient gel electrophoresis analyses. J. Environ. Radioactiv., 99 (4), $730-738$ (9 pages)

Sundh, I.; Bastviken, D.; Tranvik, L.J., (2005). Abundance, activity and community structure of pelagic methaneoxidizing bacteria in temperate lakes. Appl. Environ. Microbiol., 71 (11), 6746-6752 (7 pages).

Syakti, A. D.; Mazzella, N.; Nerini, D., (2006). Phospholipid fatty acids of a marine sedimentary microbial community in a laboratory microcosm: Responses to petroleum 
hydrocarbon contamination. Org. Geochem., 37 (11), 1617 1628 (12 pages).

Ter Braak, C. J. F., (1987). The analysis of vegetationenvironment relationships by canonical correspondence analysis. Vegetation, 69 (1), 69-77 (9 pages).

Urakawa, H.; Yoshida, T.; Nishimura, M., (2000). Characterization of depth-related population variation in microbial communities of a coastal marine sediment using $16 \mathrm{~S}$ rDNA based approaches and quinone profiling. Environ. Microbiol., 2 (5), 542-554 (13 pages).

Yannarell, A.C.; Triplett, E.W., (2005). Geographic and environmental sources of variation in lake bacterial community composition. Appl. Environ. Microbiol., 71 (1), 227-239 (13 pages).

Zeng, J.; Yang, L.Y.; Liang, Y., (2008). Spatial distribution of bacterial communities in sediment of a eutrophic lake revealed by denaturing gradient gel electrophoresis (DGGE) and multivariate analysis. Can. J. Microbiol., 54 (12), 1053 1063 (11 pages).

Zhang, L.; Yuan, X.Y.; Deng, X., (2007). Speciation of heavy metals in sediments from Lake Xuanwu and their environmental significance. Chin. J. Lake Sci., 19 (1), 6369 (7 pages).

Zink, K. G.; Mangelsdorf K., (2004) Efficient and rapid method for extraction of intact phospholipids from sediments combined with molecular structure elucidation using LCESI-MS-MS analysis. Anal. Bioanal. Chem., 380(5), 798812 (15 pages).

Zink, K.G.; Mangelsdorf, K.; Granina, L., (2008). Estimation of bacterial biomass in subsurface sediments by quantifying intact membrane phospholipids. Anal. Bioanal. Chem., 390 (3), 885-896 (11 pages).

\section{AUTHOR (S) BIOSKETCHES}

Zhao, D. Y., Ph.D., Lecturer, College of Hydrology and Water Resources, Hohai University, China. Email: dyzhao@hhu.edu.cn

Ma, T., M.Sc. student, College of Hydrology and Water Resources, Hohai University, China. Email: 290496268@qq.com

Zeng, J., Ph.D., Assistant research fellow, State Key Laboratory of Lake Science and Environment, Nanjing Institute of Geography and Limnology, Chinese Academy of Sciences, China. Email: jzeng@niglas.ac.cn

Yan, W. M., M.Sc., State Key Laboratory of Hydrology-Water Resources and Hydraulic Engineering, Hohai University, China. Email: ywm0815@hhu.edu.cn

Jiang, C. L., Ph.D., Professor, College of Hydrology and Water Resources, Hohai University, China. Email: cljianghhu@163.com

Feng, J. W., Ph.D., Lecturer, School of Civil Engineering, Hefei University of Technology, China.

Email: fengjingwei200@gmail.com

Xu, Y. N., B.Sc. student, College of Hydrology and Water Resources, Hohai University, China. Email: xuyunancindy@163.com

Zhao, H. Z., B.Sc. student, College of Hydrology and Water Resources, Hohai University, China. Email: xiaohuazhu.zhu@gmail.com

How to cite this article: (Harvard style)

Zhao, D. Y.; Ma, T.; Zeng, J.; Yan, W. M.; Jiang, C. L.; Feng, J. W.; Xu, Y. N.; Zhao, H. Z., (2011). Phospholipid fatty acids analysis of the vertical distribution of microbial communities in eutrophic lake sediments. Int. J. Environ. Sci. Tech., 8 (3), 571-580. 